\title{
Is tilapia farming financially profitable and efficient? Policy options for sustainable farming
}

\author{
Mezamun-Ara Mukta ${ }^{1},{ }^{凶 d}$. Akhtaruzzaman Khan ${ }^{1}$, Md. Rais Uddin Mian ${ }^{1}$ and Rahat Ahmed \\ Juice $^{2}$ \\ ${ }^{1}$ Department of Agricultural Finance, Bangladesh Agricultural University, Mymensingh-2202, Bangladesh \\ ${ }^{2}$ Department of Agricultural Economics, Bangladesh Agricultural University, Mymensingh-2202, Bangladesh
}

\begin{tabular}{|c|c|}
\hline ARTICLE INFO OPEN ${ }^{\text {Access }}$ & Abstract \\
\hline $\begin{array}{l}\text { Article history: } \\
\text { Received : } 22 \text { February } 2019 \\
\text { Accepted : 19 March } 2019 \\
\text { Published: } 31 \text { March } 2019 \\
\end{array}$ & \multirow{3}{*}{$\begin{array}{l}\text { Tilapia (Oreochromis niloticus) is known as 'fish for the poor' due to its low market price. However, the } \\
\text { question remains about the sustainability of this species because of high production cost and lower market } \\
\text { price. Therefore, this study examined the financial profitability, technical efficiency and tried to find out } \\
\text { the policy options for increasing the financial benefit of fish farmers. A total of } 250 \text { tilapia fish farmers } \\
\text { were selected from seven tilapia producing areas of Bangladesh. To fulfill the objectives of this study, } \\
\text { profitability, stochastic frontier production function, and sensitivity analysis were employed. Considering } \\
\text { all selected farmers, tilapia farming found a profitable business where undiscounted BCR was only1.11. } \\
\text { Among all cost items, only feed consists of } 70 \text { percent of the total production cost. The mean technical } \\
\text { efficiency level of tilapia fish farmers was } 85 \text { percent, implies that by operating at full technical efficiency } \\
\text { levels, tilapia yield could be increased from the current level of } 20.98 \text { to } 24.13 \text { tons per hectare and } \\
\text { efficient farmers found more productive than inefficient farmers. Farmer's financial benefit can be } \\
\text { increased by reducing the feed price, decreasing FCR or increasing the output price. Feed price reduction } \\
\text { or enhance the quality of feed could be effective policy options for sustaining the tilapia farming. }\end{array}$} \\
\hline $\begin{array}{l}\text { Keywords: } \\
\text { Tilapia farming, profitability, } \\
\text { technical efficiency, sensitivity } \\
\text { analysis }\end{array}$ & \\
\hline $\begin{array}{l}\text { Correspondence: } \\
\text { Md. Akhtaruzzaman Khan } \\
\text { 凶: azkhan13@yahoo.com }\end{array}$ & \\
\hline
\end{tabular}

Copyright:

(c) (i)

(C) 2019 by authors and BAURES. This work is licensed under the Creative Commons Attribution International License (CC By 4.0).

\section{Introduction}

The contribution of aquaculture is remarkable for the impressive growth in the supply of fish for human consumption as well as the fastest growing sectors of food production in the world (FAO, 2018). In terms of overall fish production, Bangladesh stood fifth all over the world and this sector is playing an increasingly important role in the economic upliftment of Bangladesh (FAO, 2018). Presently, the fisheries sub-sector contributes about 4.43 percent to national GDP, 22.21 percent to agricultural GDP and 2.75 percent to the foreign exchange earnings (BBS, 2016). Out of total fish production, aquaculture contributes 52.92 percent and has expanded rapidly all over the country (DoF, 2017). Production trend of aquaculture has also considerably increased over the last one and half a decade (DoF, 2017).

Among the aquaculture species, tilapia is one of the major species which has expanded tremendously all over the country. Tilapia as hardy, fast-growing, short term, suits in freshwater to brackish, smaller to larger water bodies, cope with different culture patterns, taste with no muscular bone becoming popular day by day (Alam et al., 2012). Consequently, overall as well as per capita production of tilapia has increased sharply from 2006 to 2016 (DoF, 2017) (Fig. 1). In the vision 2020-21, it is expected that tilapia will play an important role in

Mukta, M.A., Khan, M.A., Mian, M.R.U. and Juice, R.A. 2019. Is tilapia farming financially profitable and efficient? Policy options for sustainable farming. Journal of Bangladesh Agricultural University, 17(1): 92-98. https://doi.org/10.3329/jbau.v17i1.40669

producing 4.552 million MT fish (Rahman et al., 2015). In the vision, the government of Bangladesh (GoB) targeted to reduce 65 million hardcore poor people to 22 million where fisheries sector, especially tilapia, will contribute significantly (Rahman et al., 2015).

In recent years, tilapia farming is facing the problems of decreasing market prices, increasing feed cost with quality degradation. As a result, the production cost became high enough compared to the market price of the tilapia and the farmers are being discouraged to tilapia farming. Furthermore, the exponential increase of population creates pressure on silently decreasing cultivable land which necessitates thinking about efficient use of existing resources. So, it is being envisaged that if rising demand is not met by equally fast supply growth, shortages of fish will cause lower fish consumption, especially among the poor, and threaten food security (World Fish Centre, 2007). Therefore, tilapia production needs to be increased which can be achieved by increasing the efficiency of tilapia farmers using existing technology and encouraging them through profiting. New technology and scientific management practices that promise higher returns or lower costs are constantly being introduced. Improvements in these technology and production systems are all interlinked where research can complement traditional knowledge to improve the 
efficiency and productivity of aquaculture. Moreover, the available evidence suggests that farmers in the developing countries fail to exploit the full potential of a technology and/or make allocative errors (Ali and Flinn, 1989; Kalirajan and Shand, 1989; Bravo Ureta and Evenson, 1994; Shanmugam and Palanisami, 1994; Sharma and Datta, 1997; and Thomas and Sundaresan, 2000). Thus, the measurement of financial profitability and the technical efficiency of tilapia is an important issue from the standpoint of aquaculture development exercises in developing countries like Bangladesh. It will give pertinent use and useful information for making sound management decisions on resource allocations and for formulating aquaculture policies. Few studies on profitability and technical efficiency in different aquaculture farms had been conducted (Aktar et al., 2018; Khan et al. 2018; Sarker et al., 2016; Iliyasu et al., 2014; Alam et al., 2012; Alam, 2011; Khan, 2012; Khan and Alam, 2003; Sharma and Leng, 2000; Dey et al., 2010) but research work related to financial profitability and technical efficiency of tilapia farming in Bangladesh is very few. Therefore, this study was conducted to know, how the financial benefit can be increased through new policy intervention in developing countries for sustaining the tilapia farming.

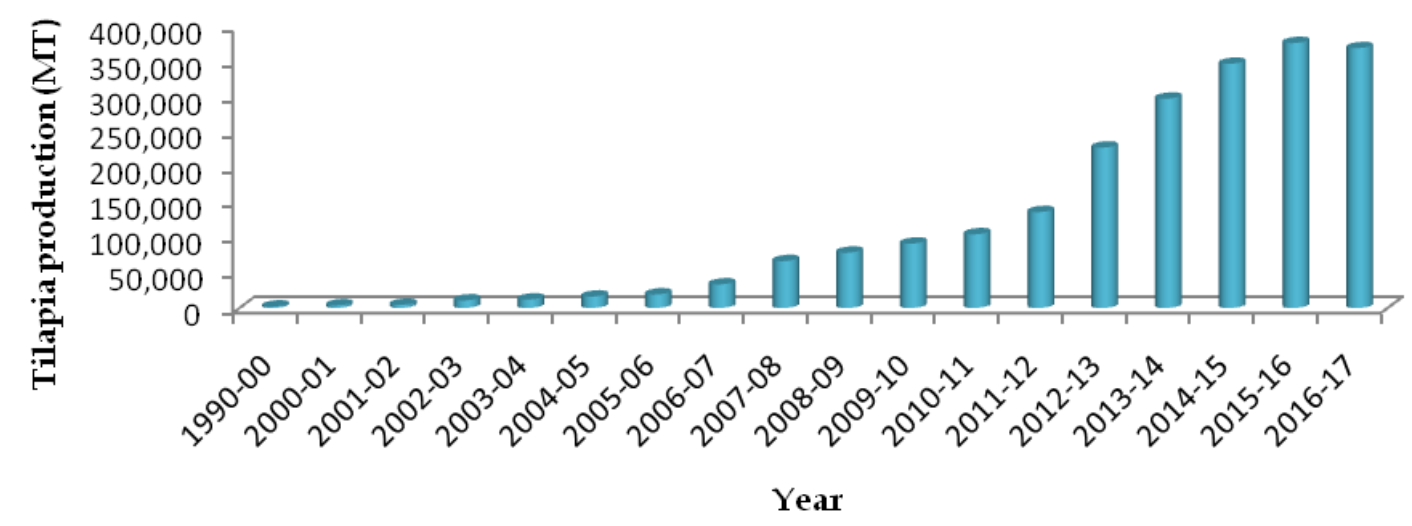

Fig. 1. Tilapia Production Trend from 1990 to 2017 Source: DoF, (1990-00 to 2016-17)

\section{Materials and Methods}

\section{Study area and sample size}

Considering the intensity of tilapia fish production, seven (7) districts were purposively selected for this study, which are Mymensingh, Cumilla, Bogura, Jashore, Bhola, Khulna, and Chattogram Afterward, 18 upazilas were selected as per production volume (on the basis of DoF statistics) from these seven districts. Finally, a total of 250 tilapia farmer were selected following the simple random sampling technique from this 18 upazilas. Data were collected through direct interviews of the respondents using a prescribed survey schedule during the months of March to June in 2016 considering the production year 2015. Each survey schedule was checked and verified to eliminate possible errors and inconsistency after the interview.

\section{Analytical technique}

Per hectare financial profitability of tilapia production from the viewpoint of individual farmers was measured in terms of net return, the benefit-cost ratio (undiscounted), gross profit margin, net profit margin, and break-even price. In addition, sensitivity analyses were performed to assess how farmers can earn financial benefit in different situations (reducing feed price and increasing output price). If the production process is not technically efficient, then resources become wasted. Therefore, it is important to know the level of technical efficiency and an optimal input combination of a farm. The Stochastic Frontier Analysis (SFA) and Data
Envelopment Analysis (DEA) are the two principal methods to measure farm efficiency. In this study, SFA was used to estimate the technical efficiency of tilapia fish farmers. Two types of functions, namely CobbDouglas and Translog dominate the technical efficiency literature. Both functional forms were tested where Cobb-Douglas found suitable for the data set.

The empirical stochastic production function for the tilapia farmers was specified as

$$
\begin{aligned}
\ln Y_{i}= & \beta_{0}+\beta_{1} \ln \left(X_{1}\right)+\beta_{2} \ln \left(X_{2}\right)+\beta_{3} \ln \left(X_{3}\right)+ \\
& \beta_{4} \ln \left(X_{4}\right)+\beta_{5} \ln \left(X_{5}\right)+V_{i}-U_{i}
\end{aligned}
$$

Where, $L n=$ natural logarithm; $Y=$ observed farm output ( $\mathrm{kg} /$ hectare); $X_{1}=$ quantity of labor (mandays/hectare); $X_{2}=$ fingerlings (no./hectare); $X_{\mathrm{a}}=$ feed $(\mathrm{kg} /$ hectare $) ; X_{4}=$ salt $(\mathrm{kg} /$ hectare $) ; X_{5}=$ lime ( $\mathrm{kg} / \mathrm{hectare})$.

Inefficiency model was used to determine the contribution of the socioeconomic variables to the observed technical inefficiency (TI) of the fish farmers. The empirical technical inefficiency effects, $U_{\mathrm{i}}$ is as follows:

$U_{i}=\delta_{0}+\delta_{1} Z_{1}+\delta_{2} Z_{2}+\delta_{3} Z_{3}+\delta_{4} Z_{4}+\delta_{5} Z_{5}+\delta_{6} Z_{6}+\omega_{i}$ Where, $Z_{1}=$ age of the respondents (years); $Z_{2}=$ family size (number); $Z_{3}=$ dependency ratio; $Z_{4}=$ education (year of schooling); $Z_{5}=$ farming experience (years); $Z_{6}$ $=$ training (days). 
Furthermore, polynomial regression model was used to estimate the relationship between efficiency and productivity of tilapia farm. This model is normally used in those situations where the relationship between dependent and explanatory variables is curvilinear and it can be expressed as:

$Y_{i}=m\left(X_{i}\right)+\delta\left(X_{i}\right) \varepsilon_{i}$

For some unknown mean and variance functions $\mathrm{m}(\cdot)$ and $\delta^{2}(\cdot)$, and symmetric errors with $\mathrm{E}()=0$ and $\operatorname{Var}()$ $=1$. The goal is to estimate $\mathrm{m}\left(\mathrm{x}_{0}\right)=\mathrm{E}\left[\mathrm{Y} \mid \mathrm{X}=\mathrm{X}_{0}\right]$, making no assumption about the functional form of $\mathrm{m}(\cdot)$.

\section{Results and Discussion}

\section{Financial Profitability of Tilapia Farming}

Human labor, fingerlings, feed, fertilizer, water cleaning cost, medicine, insecticide, lease value of land and depreciation of equipment were identified as cost items in the tilapia production process. All input costs were taken into account for one production year to calculate the per hectare cost of tilapia production. Here, it is important to mention that, tilapia is being cultured twice in a year and each culture period takes 4 to 5 months. All cost and return data have been collected for the whole year i.e. two culture periods. In the study areas, both family and hired labor were used for different activities and valued at the prevailing wage rate. Human labor was used for pond preparation, feeding, fertilizing, manuring, application of lime and harvesting of fish. Considering all locations, it was observed that about 280 labors were used for tilapia culture which cost was Tk 103600 per hectare and shared 6.04 percent of the total cost. Normally, farmers purchased fingerlings from the fry collectors and/or hatcheries and the cost was calculated on the basis of farm gate price. On an average, per hectare stocking density of fingerlings was 66227 pieces and costing was Tk 137951 consisting of 8.04 percent in total cost (Table 1).

Table 1. Per hectare cost-return and profitability of tilapia fish farming

\begin{tabular}{|c|c|c|c|c|}
\hline Heads & Quantity & $\begin{array}{c}\text { Price } \\
\text { per unit }\end{array}$ & $\begin{array}{l}\text { Value } \\
\text { (in Tk.) }\end{array}$ & $\begin{array}{c}\% \text { of } \\
\text { total cost }\end{array}$ \\
\hline Family labor (man-days) & 115 & & 42550 & \\
\hline Hired labor (man-days) & 165 & & 61050 & \\
\hline Total labor & 280 & 370 & 103600 & 6.04 \\
\hline Fingerlings (no.) & 66227 & 2 & 137951 & 8.04 \\
\hline Feed $(\mathrm{kg})$ & 34307 & 35 & 1200745 & 70.00 \\
\hline $\begin{array}{l}\text { Water cleaning cost (salt, lime } \\
\text { and water exchange) (Tk.) }\end{array}$ & - & & 75212 & 4.38 \\
\hline Medicine cost & - & & 16717 & 0.97 \\
\hline Fertilizer (kg) (Urea and TSP) & 126 & 20 & 2594 & 0.15 \\
\hline Others cost (Tk.) & - & & 95794 & 5.48 \\
\hline $\begin{array}{l}\text { A. Total variable cost } \\
\text { Fixed cost }\end{array}$ & - & & 1632613 & 95.17 \\
\hline Land lease & - & & 74100 & 4.42 \\
\hline Equipment, boat and nets & 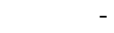 & & 7671 & 0.51 \\
\hline B. Total fixed cost & - & & 82771 & 4.83 \\
\hline Total cost $(\mathrm{A}+\mathrm{B})$ & - & & 1715384 & \\
\hline Total return $(\mathrm{Kg})$ & 20976 & 91 & 1908816 & \\
\hline Gross margin (Tk.) & - & & 276203 & \\
\hline Net return (Tk.) & - & & 193432 & \\
\hline Benefit-cost ratio (BCR) & & & 1.11 & \\
\hline $\begin{array}{l}\text { Gross profit margin (GPM) } \\
(\%)\end{array}$ & & & 14.47 & \\
\hline Net profit margin (NPM) $(9 \%)$ & & & 10.13 & \\
\hline FCR (Feed conversion ratio) & & & 1.64 & \\
\hline
\end{tabular}

Feed is the most important input for aquaculture production and farmer uses industrial pellet feed in the study area. Considering all locations, the average cost of feed was estimated at Tk 1200745 per hectare and among all cost items, it constitutes 70 percent in total cost (Table 1). The finding of this current study is consistent with Prodhan and Khan (2018), Khan (2012) and Bureau et al., (2009), where they observed that feed was the major operational cost for most fish farms, accounting for 60-75 percent of the variable cost depending on farming intensity. This is mainly because of the rising price of commercial fish feed in Bangladesh. Rising feed costs squeeze not only fish farmers, but also feed producers, driving them to search for alternatives to conventional feed ingredients to minimize their costs (Bureau et al., 2009). Furthermore, Feed Conversion Ratio (FCR) was found 1.64 implies that about $1.64 \mathrm{~kg}$ of feed was needed to produce $1 \mathrm{~kg}$ tilapia fish. In recent years, poor-quality feed with low nutritional value is the main cause of low productivity (Bureau et al., 2009). Again, countries like Bangladesh, commercial feed is simply beyond the reach the most small-scale farmers, limiting their ability to intensify aquaculture production. Therefore, relatively high fish feed prices favor large, vertically integrated fish farms; small-scale farms are becoming increasingly vulnerable to rising feed costs and highly competitive market. To make tilapia farming more flexible and input efficient, reducing feed cost is the most concerning part to look at.

Water cleaning is one of the main important operational activities in fish farming. Pond water becomes unhealthy due to regular use of industrial feed and lack of proper water exchange facilities. Therefore, farmers take different actions to maintain water quality such as application of lime, salt, aqua clean, gerolux, potash, timsen, bleaching powder, and zeolite etc. In addition, farm those have water exchange facility uses shallow tube well for exchanging water. On average, water cleaning cost per hectare was estimated at Tk 75212 and it was 4.38 percent of the total cost. Tilapia farms also incurred some other costs such as harvesting, electricity, torchlight, rope, umbrella, commission for the caretaker, mobile bill, and repair of guard shed etc. and it was estimated at Tk 95794 thus shared 5.48 percent of the total cost. The average total variable cost of tilapia cultivation was estimated at Tk 1632613. On the other hand, land lease value and depreciation cost of different capital items were considered as the fixed cost which was estimated at Tk. 82771 consists of 4.83 percent of total production costs.

The total return of tilapia farm was calculated by multiplying the total amount (sold and consumed) of production by their respective market prices. On average, productivity was found $20976 \mathrm{~kg}$ per hectare and the average market price of per $\mathrm{kg}$ tilapia was estimated at Tk.91. Profit from per hectare of pond was estimated at Tk 193432 with BCR only 1.11 which is lower than other fish species (Alam et al., 2006; Faruque 
et al., 2005). Furthermore, gross profit margin (GPM) and net profit margin (NPM) was $14.47 \%$ and $10.13 \%$, respectively which was significantly lower than shrimp farming in Bangladesh (Shawon et al. 2018).

\section{Technical Efficiency Analysis}

The maximum-likelihood estimates of the parameters for the stochastic production frontier model and those for the technical inefficiency model for tilapia production are presented in Table 2. Cobb-Douglas production function and a single linear functional form were used in the frontier production function and inefficiency function, respectively. Several variables such as human labor, number of fingerlings, quantity of feed, salt, and lime were used in the tilapia production process. Most of the coefficient of the stochastic frontier or output elasticities of input had expected sign. The coefficient of labor, feed, salt, and lime had positive signs and were statistically significant at the 1 percent level, implying that increasing the amount of these inputs helps the farmers increase their output. On the other hand, the fingerlings quantity was found insignificant. It clearly indicates that the fingerlings had no significant effects on tilapia production. The reason was that farmers did not use the appropriate numbers of fingerlings in the pond that was recommended by fisheries scientist. Output elasticity of input was the highest for feed (0.558) followed by labor (0.204), salt (0.142), lime (0.126) and fingerling (0.098).

Table 2. Maximum likelihood estimates of stochastic production function and inefficiency function

\begin{tabular}{llr}
\hline Variables & Coefficient & t-value \\
\hline Production function & & \\
Labor (man-days) & $0.204^{* * *}$ & 3.971 \\
Fingerling (number) & 0.098 & 1.076 \\
Feed (kg) & $0.558^{* * *}$ & 14.278 \\
Salt (kg) & $0.142^{* * *}$ & 2.821 \\
Lime (kg) & $0.126^{* * *}$ & 3.497 \\
Constant & 0.224 & 0.225 \\
Gamma & $0.909^{* * *}$ & 43.739 \\
Inefficiency function & & \\
Age & $-1.024^{* * *}$ & -2.387 \\
Family size & $-0.961^{* * *}$ & -2.737 \\
Dependency ratio & -0.766 & -0.282 \\
Education & -0.057 & -0.537 \\
Farming experience & $-0.072^{* * *}$ & -6.426 \\
Training & $-0.675^{* * *}$ & -2.815 \\
Constant & $5.884^{* * *}$ & 2.847 \\
Mean Efficiency & \multicolumn{2}{c}{0.847} \\
\hline
\end{tabular}

*** indicates statistically significant at $1 \%$ level

$* *$ indicates at $5 \%$ level and * indicates at $10 *$ level

Technical efficiency of any farmer is determined by socio-economic and demographic factors (Kalirajan and Shand, 1989; Bhende and Kalirajan, 2007). Therefore, the contribution of socioeconomic variables to the technical inefficiency (TI) of tilapia fish farmers was determined by using the inefficiency model. Age of farmers, family size, dependency ratio, education, farming experience, and training were taken into account to estimate the inefficiency effects. Since the dependent variable of the inefficiency model was defined in terms of technical inefficiency, a farm-specific variable associated with the negative (positive) coefficient will have a positive (negative) impact on technical efficiency. Age, family size, farming experience, and training were significant at the 1 percent level and had a positive impact on technical efficiency (negative impact on technical inefficiency) (Table 2). As old farmers have normally more experience than younger farmers and this experience along with better training services make them able to reduce the production inefficiencies and losses by gaining more information. Education and dependency ratio did not seem to have any effect on technical efficiency individually as they were all statistically insignificant. The $\gamma$-parameter was found to be 0.91 which was estimated to be close to 1 and highly significant. Although the $\gamma$-parameter cannot be interpreted as the proportion of the total variance explained by the technical inefficiency effects, the result indicates that inefficiency factors had a significant impact on tilapia production. The mean technical efficiency of tilapia fish farmers of Bangladesh was found 85 percent varying from 26 to 99 percent and surprisingly, not a single farm appears as fully technically efficient (Table 2). The findings imply that farmers were operating 15 percent lower than the production frontier given the level of technology which was similar to another finding on the efficiency of cage fish farming in Peninsular Malaysia resulting an estimated mean technical efficiency score of 79 percent (Iliyasu et al., 2014). This finding was also consistent with Islam et al., (2004); Khan et al., (2010); Islam et al., (2012). By operating at full technical efficiency levels, tilapia yield could be increased from the current level of 20.98 to 24.13 tons per hectare.

The result also reveals that about 54.4 percent of tilapia farmers have technical efficiency scores ranging from $\geq$ 0.80 to $\leq 0.90$ and 28.8 percent operate above 0.90 level (Fig. 2) which implies that most of the farmers operate above 80 percent efficiency level. Furthermore, only 3.6 percent of farmers operate at less than $60 \%$ level of technical efficiency (Fig. 2). This technical efficiency level of tilapia farmers appears to be higher than the previous study of Bangladesh by Alam et al., (2012) were found mean technical efficiency score $78 \%$ and $32 \%$ farmers have technical efficiency scores ranging between 70 and $80 \%$ while $28 \%$ operate between 90 and 99\% level.

Farm productivity mainly depends on the scientific and efficient use of different inputs. To examine whether efficient farmers are productive or not, polynomial regression was used. Fig. 3 shows that productivity increases with the increase of the efficiency of the farmers which means if the farmer uses different inputs efficiently then the productivity will also increase. Therefore, knowledge of scientific management practices is essential for getting higher productivity and financial benefit. 


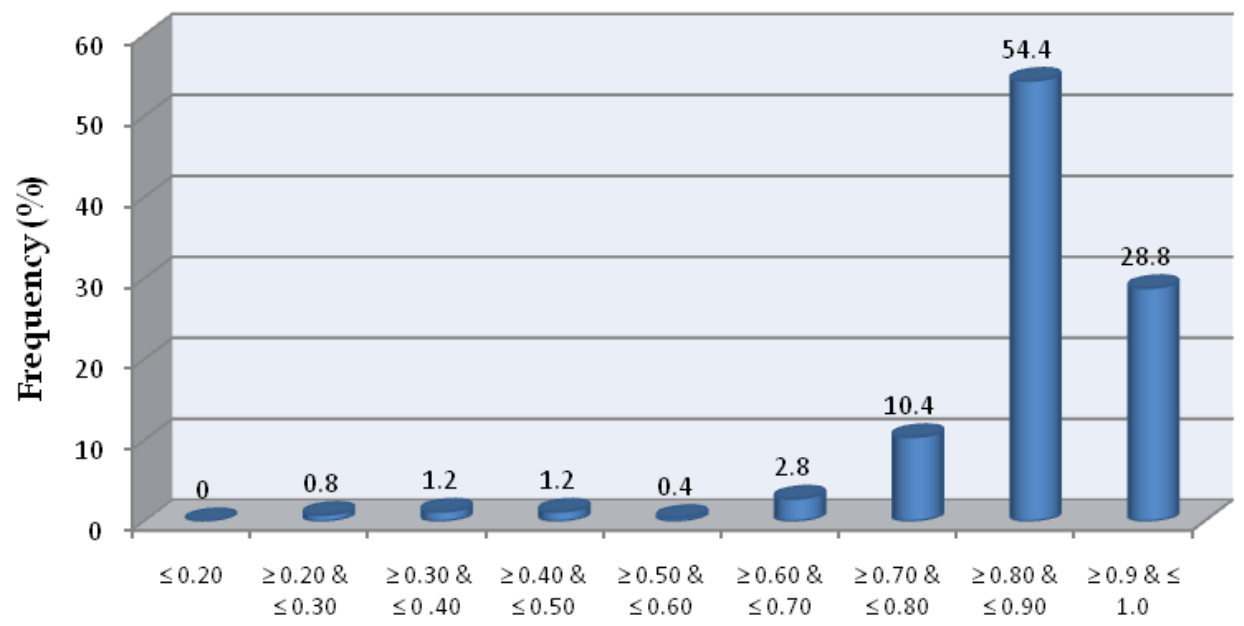

Efficiency score

Fig. 2. Frequency distribution of technical efficiency scores

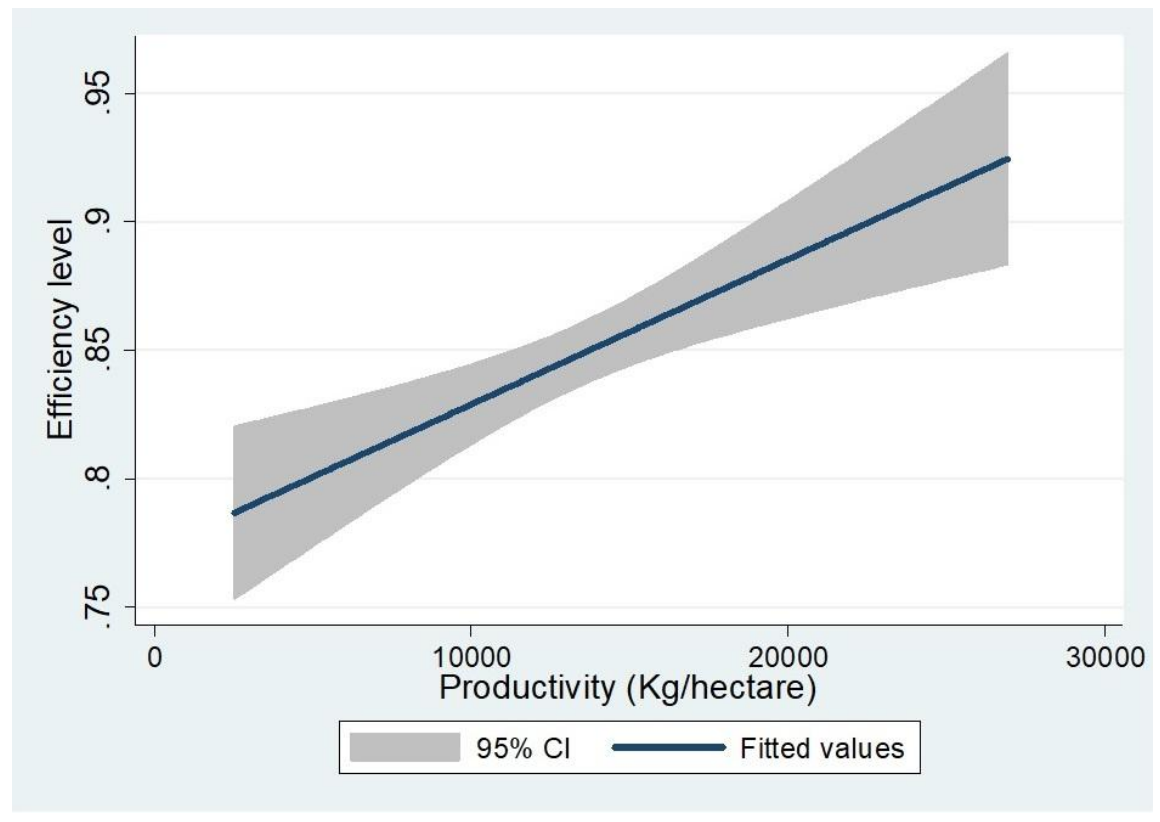

Fig. 3. Relationship between efficiency and productivity

\section{Sensitivity Analysis}

Due to low market price and high input cost, farmers are being discouraged to culture tilapia and it was also observed from the field level that farmers were switching from tilapia to other indigenous fish species to get the higher financial benefit. Therefore, the government, as well as relevant organizations, need to take some policy for sustainable tilapia farming. This study found that only feed cost consists of about 70 percent of total production cost, and output price was low compared to other fish species. Therefore, there are rooms to introduce some policies. To generate new policy, this study tried to show the effects of changes in feed and output price on financial benefit. Five scenarios were evaluated with the business as usual (Table 3). Other things remaining the same, if the feed price is reduced by only 10 percent, then BCR becomes 1.2 and farmers can earn profit about Tk.15 from per $\mathrm{kg}$ of fish which was Tk. 9 in the business as usual situation and the variable cost of per $\mathrm{kg}$ fish can be reduced from Tl.78 to Tk.72. In the same way, if the output price is increased by only 10 percent with other things remain the same, BCR becomes 1.22 and NPM reached 18.3 percent from 10.13 percent of business as usual. In this situation, the benefit from per $\mathrm{kg}$ of fish reached $\mathrm{Tk}$. 18.32 which is higher than the reduction of 10 percent feed price implies that the farmer gets more benefit from the increase in output price compared to feed price reduction (Table 3). In addition, another two situations were analyzed as only " 5 percent reduction in feed price and 5 percent increase in output price", and " 10 percent reduction in feed price and 10 percent increase in output 
price" (Table 3). Results reveal that Tilapia farmers can be financially benefited through implementing both policies, where by reducing 10 percent feed cost and 10 percent increase of output price, BCR become 1.32 and net profit margin reached to 24.02 percent. Finally, another option has been analyzed where FCR was reduced by 10 percent meaning feed use reduction by 10 percent for producing per kilogram fish. It is only possible when feed quality can be increased with other things remain the same. From the above results, it can be concluded that the reduction of feed price, enhance the quality of feed or an increase of output price may be an effective policy for sustainable tilapia farming.

Table 3. Sensitivity analysis of feed and output price changes and its effects on financial benefit

\begin{tabular}{|c|c|c|c|c|c|c|}
\hline Scenario & BCR & GPM & NPM & BEP & VCK & BKF \\
\hline Business as usual & 1.11 & 14.47 & 10.13 & 81.78 & 77.83 & 9.22 \\
\hline Feed price reduced by $10 \%$ & 1.20 & 20.76 & 16.42 & 76.05 & 72.11 & 14.95 \\
\hline Feed price reduced by $20 \%$ & 1.29 & 27.05 & 22.71 & 70.33 & 66.38 & 20.67 \\
\hline Output price increased by $10 \%$ & 1.22 & 22.25 & 18.30 & 81.79 & 77.83 & 18.32 \\
\hline $\begin{array}{l}\text { Feed price reduced by } 5 \% \text { and output } \\
\text { price increased by } 5 \%\end{array}$ & 1.21 & 21.54 & 17.41 & 78.92 & 74.97 & 16.63 \\
\hline $\begin{array}{l}\text { Feed price reduced by } 10 \% \text { and output } \\
\text { price increased by } 10 \%\end{array}$ & 1.32 & 27.96 & 24.02 & 76.05 & 72.11 & 24.05 \\
\hline FCR reduced by $10 \%$ & 1.19 & 20.25 & 16.12 & 76.33 & 72.39 & 14.67 \\
\hline
\end{tabular}

BCR: Benefit-cost ratio; GPM: Gross profit margin; NPM: Net profit margin; BEP: Break-even price;

VCK: Variable cost per kg fish; BKF: Benefits from per $\mathrm{kg}$ fish

\section{Conclusions and Policy Recommendation}

Tilapia farming has expanded tremendously in Bangladesh over the last two decades. Throughout the country, commercial tilapia farms follow semi-intensive farming practices where the industrial feed is the main input of production and has become very expensive to the producer. Furthermore, the market price of tilapia is very low compared to other fish species which leads to less financial benefit from tilapia farming. In this study, tilapia farming found a financially profitable business where BCR was low compared to other fish species. Among all cost items, only feed cost was about $70 \%$ of the total production cost. Labor use, number of fingerlings per hectare, amount of feed, salt, and lime were contributed significantly to the production of tilapia. Age of farm operators, education, training, and experience were significant determinants of technical inefficiency. Per hectare yield could be increased by 15 percent with the existing technology if farmers could run at the frontier. Thus, given the levels of existing technologies and resource use, the sample farms could increase their average yield from the existing 20.98 to 24.13 tons/ha by using their existing resources more efficiently. Department of Fisheries and other relevant organization can play a vital role in improving the technical efficiency of tilapia farmers through better training on stocking, feeding and fertilizing ponds. In this case, leaflet distribution on scientific tilapia farming may be one of the best ways, which may help to improve fish production practices. Farmers in the study areas are not able to use inputs, especially feed at optimum level because of the higher price and also output price was very low as their expectation. Reduction of feed price, FCR reduction though increasing feed quality and the increase of tilapia price found effective ways for enhancing the financial benefit of tilapia farmers. But increases in output price depends on several factors such as demand, supply, and consumer preferences. In addition, increases in output prices hamper the consumer's welfare. Therefore, the reduction of feed price or enhance the quality of feed could be an effective policy for sustainable tilapia industry. Government can provide subsidy on fish feed or can introduce tax rebate policy in imported feed ingredient for reducing the feed price. Furthermore, the feed market is mainly controlled by very few companies and earn the supernormal profit that leads to increase the feed price. Therefore, the government's monitoring system in the feed industry is to be strengthened and new regulatory policy needs to be introduced for sustaining the industry.

\section{References}

Akter, S.S., Khan, M.A., Prodhan, M.M. and Mukta, M.A. 2018. Farm size, productivity and efficiency nexus: The case of pangas fish farming in Bangladesh. Journal of the Bangladesh Agricultural University, 16(3): 513-522. https://doi.org/10.3329/jbau.v16i3.39449

Alam., F. 2006. Measuring technical, allocate and cost efficiency of pangas (Pangasiushy pophthalmus: Sauvage fish farmers of Bangladesh. Aquaculture Research, 42(10):1487-1500 https://doi.org/10.1111/j.1365-2109.2010.02741.x

Alam, M.F. and Khan, M.A. 2012. Technical efficiency in tilapia farming of Bangladesh: a stochastic frontier production approach. Aquaculture International, 20(4): 619-634. https://doi.org/10.1007/s10499-011-9491-3

Ali, M. and Flinn, J.T. 1989. Profit efficiency in basmati rice production, American Journal of Agricultural Economics, 71 (2): 303-310. https://doi.org/10.2307/1241587

BBS. 2016. Statistical Yearbook of Bangladesh, Bangladesh Bureau of Statistics, Ministry in Planning, Government of the people's Republic of Bangladesh, Dhaka.

Bravo-Vrata, B.E., and Evenson, R.E. 1994. Efficiency in agricultural production: The case of peasant farmers in eastern Paragnay, Agricultural Economics, 10(1): 27-37. https://doi.org/10.1016/0169-5150(94)90037-X

Bureau, D.P. and Cho, C.Y. 2009. Ingredient quality: an essential factor in the formulation of cost-effective aquaculture diets. In: Expanding Agriculture Co-Product Uses in Aquaculture Feeds Workshop Proceeding, pp: 234-258.

Dey, M.M., Kumar, P., Paraguas, F.J., Chen, O.L., Khan, M.A. and Srichantuk, N. 2010 Performance and nature of genetically improved carp strains in Asian countries. Aquaculture Economics and Management, 14(1), 3-19. 
https://doi.org/10.1080/13657305.2015.996679

DoF. 1990-91 to 2016-17. Fishery Statistical Yearbook of Bangladesh, Department of Fisheries, Ministry of Fisheries and Livestock, Dhaka, Bangladesh.

DoF. 2017. Yearbook of Fisheries Statistic of Bangladesh, Department of Fisheries, Ministry of Fisheries and Livestock, Government of the People's Republic of Bangladesh.

FAO. 2018. The state of world fisheries and aquaculture. Meeting the sustainable development goals. Rome, Italy.

Farrell, M.J. 1957. "The measurement of productive efficiency". J R Stat Soc Series A 120(III):253-281 (part 30).

Faruque, S.M.A.S. 2005. "A Comparative Economic Analysis of Carp and Pangas Culture in Some Selected Areas of Mymensingh District". M.S. Thesis, Department of Agricultural Economics, Bangladesh Agricultural University, Mymensingh.

Iliyasu, A., Mohamed, Z. A., Ismail, M.M., Amin, M.A., and Mazuki, H. 2014. "Technical efficiency of cage fish farming in Peninsular Malaysia: a stochastic frontier production approach". MS Thesis, Department of Agribusiness and Information Systems, Faculty of Agriculture, University Putra Malaysia

Islam, K.M.Z., Sumelius, J. and Backman, S. 2012. Do differences in technical efficiency explain the adoption rate of HYV rice? Evidence from Bangladesh. Agricultural Economics Review, 13(1): 93-110.

Islam, M.R., Hossain, M. and Jaim, W.M.H. 2004.Technical efficiency of farm producing Transplanted Aman rice in Bangladesh: A comparative study of aromatic, fine and coarse varieties. Bangladesh Journal of Agricultural Economics, 27(2): $1-24$

Kalirajan, K.P. and Shand, R.T. 1989. A generalized measure of technical efficiency, Applied Economics, 21: 25-34. https://doi.org/10.1080/772284229

Khan, M.A., Guttormsen, A. and Roll, K.H. 2017. Production risk of pangas (Pangasius hypophthalmus) fish farming. Aquaculture Economics and Management, 22(2):192-208 https://doi.org/10.1080/13657305.2017.1284941 https://doi.org/10.1080/13657305.2017.1284941

Khan, M.A. 2012. Efficiency, Risk and Management of Fisheries Sector in Bangladesh, Doctoral Thesis, UMB School of Economics and Business, Norwegian University of Life Sciences, Norway.

Khan, A., Huda, F. A. and Alam, A. 2010. Farm household technical efficiency: A study on Rice producers in selected areas of
Jamalpur district in Bangladesh. European Journal of Social Sciences, 14(2): 262-271.

Khan, M.A. and Alam, F. 2003. Technical Efficiency of the Hatchery Operators in Fish Seed Production Farms in Two Selected Areas of Bangladesh. Bangladesh Journal of Agricultural Economics, 26(1): 55-70.

Bhende, M.J. and Kalirajan, K.P., 2007. "Technical Efficiency of Major Food and Cash Crops in Karnataka (India)", Indian Journal of Agricultural Economics, 62(2): 176-192.

Prodhan, M.M.H. and Khan, M.A. 2018. Management practice adoption and productivity of commercial aquaculture farms in selected areas of Bangladesh. Journal of the Bangladesh Agricultural University, 16(1): 111-116. https://doi.org/10.3329/jbau.v16i1.36491

Rahman, A.K.A. 2015. "Freshwater fishes of Bangladesh. 2nd Edn., Zoological Society of Bangladesh, Dhaka, Bangladesh, ISBN-13: 394.

Sarker, M.A.A., Arshad, F.M., Alam, M.F., Mohamed, Z.A. and Khan, M.A. 2016. Stochastic modeling of production risk and technical efficiency of Thai koi (Anabas testudineus) farming in Northern Bangladesh. Aquaculture Economics \& Management, 20(2):165-184. https://doi.org/10.1080/13657305.2016.1156189

Shanmugam, T.R. and Palanisami, K. 1994. Measurement of economic efficiency - Frontier function approach. Journal of Indian Society of Agricultural Statistics, 45(2): 235-242.

Sharma, K.R. and Leung, P.S., 2000. Technical efficiency of carp pond culture in south Asia: an application of a stochastic metaproduction frontier model. Aquaculture Economics \& Management , 4(3\&4):169-189. https://doi.org/10.1080/13657300009380268

Sharma, V.P. and Datta, K.K. 1997. Technical efficiency in wheat production on reclaimed alkali soils. Productivity, 38 (2): 334-338.

Shawon, N.A.A., Prodhan, M.M., Khan, M.A. and Mitra, S. 2018. Financial profitability of small scale shrimp farming in a coastal area of Bangladesh. Journal of Bangladesh Agricultural University, 16(1): 104-110. https://doi.org/10.3329/jbau.v16i1.36490

Thomas, K. and Sundaresan, R. (2000) Economic efficiency of rice production in Kerla, The Bihar Journal of Agricultural Marketing, 8 (3): 310-315.

World Fish Center. 2007. Aquaculture, fisheries, poverty and food security. The World Fish Center, Penang. 